\title{
Polymer concrete and fibre concrete as efficient materials for manufacture of gear cases and pumps
}

\author{
Kassym Yelemessov ${ }^{1}$, Leonid Krupnik ${ }^{1}$, Sayin Bortebayev ${ }^{1}$, Bauyirzhan Beisenov ${ }^{1}$, Dinara \\ Baskanbayeva $^{1, *}$, and Akzhan Igbayeva ${ }^{1}$ \\ ${ }^{1}$ Satbayev University, 050013, Almaty, Satpayev Str., 22, Republic of Kazakhstan
}

\begin{abstract}
The paper describes the results of investigations on application of composite materials - polymer concrete and fibre concrete for manufacture gear cases of mechanisms used in mining and metallurgical industry centrifugal pump casings. The methods of establishing efficient compositions of polymer concrete and fibre concrete, based on a filler with gapped grading in which the pinholes in coarse fractions are filled with smaller fractions have been developed. After hardening, such mixtures have the strength 1.5 ...2 times higher than the items made of metal. The efficient additive of steel fibre to fibre concrete has been identified which improves the strength characteristics. The regularities of the impact on the strength and structure of polymer concrete and fibre concrete of the rotation frequency of the working element of the mixer and time of mixing the mixture components are identified. TS-250 gear and centrifugal pump casings are made by casting method and are tested on a test bed. The results obtained make it possible for us to recommend the developed compositions of polymer concrete and fibre concrete for application in engineering industry to manufacture gear and centrifugal pump casings.
\end{abstract}

\section{Introduction}

The modern stage of industrial revolution 4.0 is characterized by the widespread use of new constructional materials characterized by improved technological properties in comparison with traditional metals: cast iron, steel, aluminum, etc. One of the strands of expansion of the field of use of such materials is their transition from the areas where they are already applied in new industry sectors. Polymer concrete and fibre concrete are worth noting among such materials widely used in construction industry. These composites are quite good to use in engineering industry, in particular for manufacture of equipment for mining and metallurgical complex $[1,2]$.

A significant amount of equipment used in mining enterprises and metallurgical plants operates in difficult conditions: work with aggressive substances, high dust content, sharp change of temperature, transportation of liquids and highly abrasive slurry, etc. These factors require to increase the thickness of casings of a number of apparatus and

\footnotetext{
*Corresponding author: baskanbaeva@mail.ru
} 
mechanisms during their manufacture, what leads to excessive metal consumption, complexity of maintenance and increase of cost. It is expedient to replace the traditionally used metals with composite materials which have improved characteristics. [3, 4].

The analysis of equipment used in mining and metallurgical sector showes that each enterprise operate a big number of centrifugal pumps and gears. Upgrading of their casings through change of materials they are made of composite materials, is being a topical issue.

As mentioned above the composite polymer concrete and fibre concrete are quite widely used in construction materials industry. They are quite thoroughly researched [4, 5]. However, in engineering industry, especially for mining and metallurgical sector equipment, such researches are almost not available and this prevents the application of composite materials instead of traditional ones.

For this reason the authors from Kazakh National Research Technical University named after K.I. Satpayev (Satbayev University) carried out special researches on application of polymer concrete to manufacture the gear cases and fibre concrete to manufacture the centrifugal pump casings (volutes). In this respect, the following issues were resolved:

- selection of polymer concrete and fibre concrete efficient compositions;

- study of the impact of basic factors on the strength of items made from polymer concrete and fibre concrete;

- development of the technology for manufacture of gear and pumps casings from the proposed composite materials;

- manufacture and testing of test samples of these items.

The results of these studies are described in this report.

\section{Methods}

During the studies a complex methodology was applied, which included analytical review of sources of literature, theoretical studies of polymer concrete and fibre concrete mixtures structures, experimental studies of the impact on the methods of preparation of mixtures and technology of casting the gear and pumps casings of different factors with verification of the results through casting and testing of finished products made from polymer concrete and fibre concrete. Experimental studies were carried out on special test beds, and their results were processed by the methods of mathematical statistics on standard methods [4]. This ensured high confidence of acquired results and allowed development of technological manuals on preparation of polymer concrete and fibre concrete mixtures and technology of casting the gear and centrifugal pumps casings from them.

\section{Results and discussion}

Polymer concrete is a composite material, which consists of mineral aggregates, fillers, and a polymer resin acting as a binding material. This makes it possible to create a sound material, which is characterized by high performance. Fibre concrete is a sort of polymer concrete in which fibre is quite evenly distributed acting as a reinforcing material. In this case, fibre is a microreinforcement.

As the studies show, basic properties of polymer concrete and fibre concrete are identified by chemical nature of synthetic resin, type and content of fine partical fillers. Coarse fractions of aggreagates (crushed stone and sand), performing mainly the role of a skeleton, impact the basic physical and mechanical properties to a lesser extent.

Both for polymer concrete and fibre concrete, the physical and mechanical properties, manufacturability and cost effectiveness depend on correctly selected components and their ratio in a composite material. Special studies were performed on this issue. 
One of the basic issues of application of polymer concrete and polymer fibre as a construction material is the most suitable mixture composition. The first of the studied issues is the selection of aggregate components and a binding material. The analysis of literature and preliminary studies showes that it is expedient to use rubble or granite crushed stone and quartz sand as an aggregate, and quartz flour as a filler. The best binding material is considered to be a polyester resin with a low viscosity during kneading and low shrinkage during hardening.

A mixture made from quartz sand is the best from all aspects. The sand does not absorb the resin and it is spent only on coating its particles, has great strength transmitted to the finished product. To prepare the mixture you need dry quartz sand calibrated by fractions. Naturally, it should not contain clay inclusions, because this is an additional consumption of resin and shrinkage of a mixture in the manufacture of the product.

Following some studies, in particular, 3D modeling, it has been detected that for the heaviest coverage of air cavities in the mixture, it should have gapped grading, i.e. consist of 2-3 fractions. The grain sizes of each fraction should differ from each other by an order of magnitude approximately.

Using the aggregate and filler with a gapped grading it is possible to obtain the most efficient mixture structure. In this case, quartz flour fills the holes between grains of quartz sand and this mixture fills the holes between grains of coarse aggregate - the crushed stone.

Theoretical and experimental studies allowed us to develop the methods for choosing the ratio of components in the composition of a composite mixture. It is expedient to start the forming of a mixture with a large fraction. It ensures the greatest resin saving in the mixture, gives the product a particular strength, but cannot do without the smaller fractions, to support the mixture from demixing. The upper limit of the size of a grain is the wall thickness of a product. To achieve the best filling of a mixture upon casting, the size of the biggest granules should not exceed $1 / 3$ of this thickness. The cast product wall thickness is approximately $1 \mathrm{~cm}$. It turns out that it is possible to use the sand of $10 \mathrm{~mm} / 3=3.3 \mathrm{~mm}$ fraction. However, the practice of casting showed that such big granules leave on the surface of the product covered with a gelcoat a large and not always desirable shagreen. The practice also shows that if covered in a standard coating of a gelcoat $(0 . \mathrm{mm})$, the granules of up to $1.2 \mathrm{~mm}$ do not result in steel shagreening. Thus, it can be stated that the most efficient coarse fraction should be $0.8-1.2 \mathrm{~mm}$.

For heavy coverage the next fraction should be smaller by an order of magnitude than coarse fraction (this is confirmed by 3D modeling), i.e. $0.1-0.3 \mathrm{~mm}$.

The smallest fraction should make up $0-0.02 \mathrm{~mm}$.

Taking into account that small fraction is added to the mixture in a small quantity it does not particularly affect the cost. For this reason, in cases when obtaining the quartz flour is a problem, it is admissible to replace it by aluminum hydrate.

It became possible to determine the sizes of sand grains most suitable for a densegraded mixture through construction of $3 \mathrm{D}$ model. But the most important here is quantitative ratio of the components in the polymer concrete mixture.

The rational ratio of the filler fraction can be determined based on Fuller formula. Taking into account that fraction sizes can differ from estimated one, the formula for automatic calculation of the amount of sand by fractions is used.

Computer modeling showed that for the case under consideration the number of coarse fraction should be $59 \%$, average $28 \%$, small $13 \%$. Inconsiderable amount of small fraction required for filling the spaces between the larger fractions favorably impacts the amount of resin required for the mixture, as the small fraction thickens the composite mixture most of all due to the large wetted surface area.

The amount of binding material in a mixture plays a critical part. Its insufficiency results in impossibility to bind all components firmly into a solid mass, while its excess 
content will adversely affect the economical efficiency.

For fibre concrete the amount and type of fibre added to composite material are the most important.

Fibre is used as a reinforcing element to improve physical and technical properties of the composite.

As a result of studies, steel fibre is applied for fibre concrete used in manufacture of centrifugal pump casings. It improves the stability of fibre concrete to mechanical effects, its fibres are characterized by good adhesion properties and thanks to this form an oxygen mixture. The steel fibre grains exclude the occurrence of cracks, peeling of the surface or the occurrence of plastic deformations.

Steel fibre with the following characteristics: fibre length $23.0 \mathrm{~mm}$, diameter $0.6 \mathrm{~mm}$ was used in the experiments.

The composition of fibre in fibre concrete should be in specific limits ensuring specified characteristics of fiber concrete products. The volume fraction of fibre in the product should be large enough in order that load share perceived by it is as much as possible. However, if the fibre content in a material exceeds a certain level, it leads to deterioration of fibre concrete properties due to the fact that the mixture is not able to penetrate in all fibres. As a result, the adhesion of fibres with the components of the mixture deteriorates and holes are formed in the product that reduce the strength of the material.

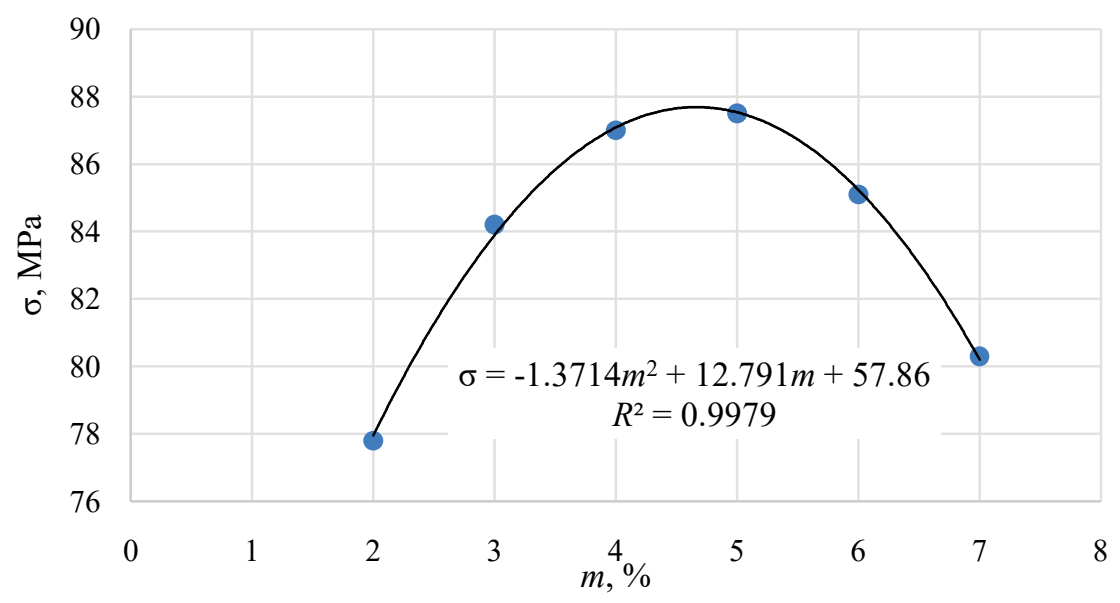

Fig. 1. Impact of fibre consumption on fibre concrete strength $\sigma=f(m)$.

Physical experiments performed showed that the most efficient content of fibre in the mixture is $4 . . .5 \%$.

Based on checked theoretical and experimental studies the most efficient content of polymer concrete and fibre concrete mixtures were recommended which comply with the requirements set to gear and centrifugal pump casings manufacture by their characteristics. This content is specified in Table 1 below.

To determine the technological parameters for preparation of mixtures to manufacture gear and centrifugal pumps casings from composite materials the rational speed of rotation of the working element of the mixer of the mixing time of the components was experimentally determined. To obtain an isotropic material after hardening polymer concrete and fiber concrete, it is necessary that the mixture is homogeneous. This is possible to ensure only through specific frequency of rotation of working element of the mixer and the time of mixing the components. Empirical dependences of the influence of these factors on the strength of hardened polymer concrete and fibre concrete were experimentally obtained. 
The influence of the rotation frequency of the working body of the mixer is described by the equation:

- for polymer concrete

$$
\sigma_{p}^{n}=0.0125 \cdot n+68.896 \mathrm{MPa}, 400<n<600
$$

- for fibre concrete

$$
\sigma_{f}^{n}=89.449 \cdot \mathrm{e}^{0.0002 \cdot n} \mathrm{MPa}
$$

where $n$ - rotation frequency

Impact of the time of mixing on the strength

- for polymer concrete

$$
\sigma_{p}^{t}=7.5966 t+56.988 \mathrm{MPa}, 1<t<4
$$

- for fibre concrete

$$
\sigma_{f}^{t}=2.1257 \cdot t+93.212 \mathrm{MPa}
$$

where $t$ - the time of mixing, min.

It is identified that the most efficient rotation frequency of the working element is $\mathrm{n}=800-1000 \mathrm{~min}^{-1}$, and the time of mixing shall make up $t=4 \mathrm{~min}$.

According to the results of carried out studies the gear case (Figure 2) and pump casing (Figure 3) were manufactured through casting. Both items passed bed tests and showed good results in operation.
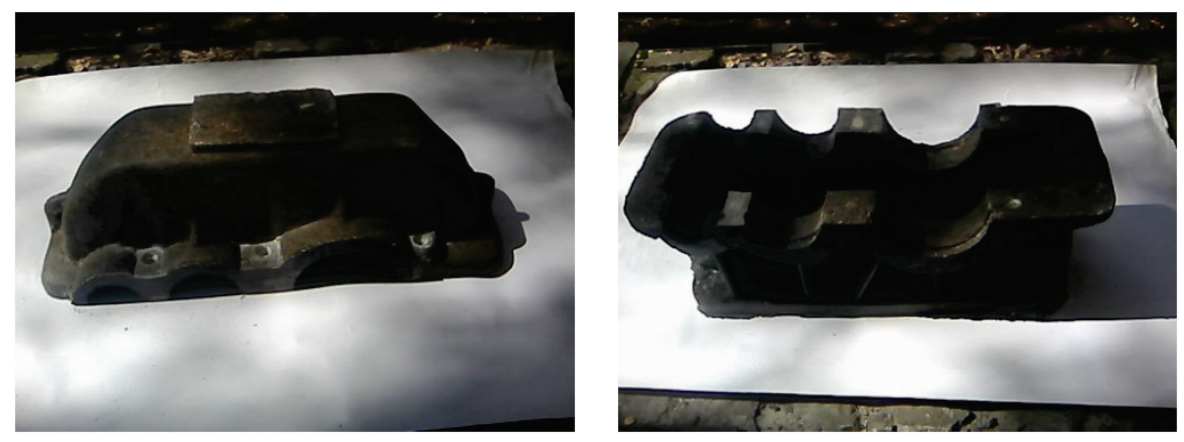

Fig. 2. Finished gear case.

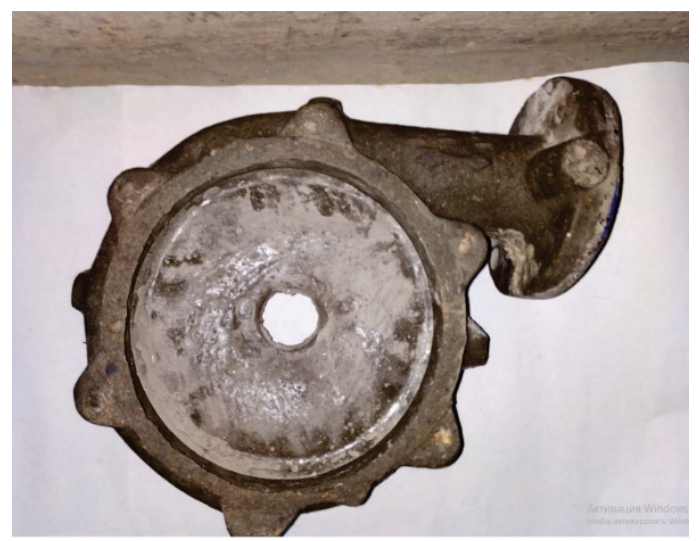

Fig. 3. Finished volute casing. 


\section{Conclusion}

The studies performed made it possible to make the following conclusions.

1. Polymer concrete and fibre concrete by their characteristics comply with the requirements set to materials for gear and centrifugal casings manufacture to full extent.

2. The developed methods of selection of the content of polymer concrete and fibre concrete mixtures make it possible to ensure obtaining of efficient mixtures that guarantee required physical and mechanical properties.

3. The obtained conformities describing the influence of the rotation frequency of the working element of the mixer and the time of mixing the components ensure obtaining of homogeneous mixtures, what guarantees the isotropic characteristics of hardened mixtures.

4. Gear and centrifugal pumps casings made from polymer concrete and fibre concrete manufactured by casting method do not require additional mechanical processing and demonstrated good quality during testing.

5. Items made from polymer concrete and fibre concrete 2.5...3.0 times easier than analogues manufactured from metal, have $30 \ldots 40 \%$ higher strength that allows to reduce the thickness of items by $20 \ldots 25 \%$.

\section{Reference}

1. A. Borisiuk, Iu. Ziatiuk. (2016). Issledovanie deformatsionnykh kharakteristik fibrobetona so talnoi fibroi. Vestnik Belorussko-Rossiiskogo universiteta, 3(52)

2. V.S. Kostyshyn, I.I. Yaremak. (2017). Mathematical model of reliability and efficiency of pumping unit of an oil pumping station. Naukovyi Visnyk Natsionalnoho Hirnychoho Universytetu, 5

3. Abdulhadiб M. (2014). A comparative study of basalt and polypropylene fibers reinforced concrete on compressive and tensile behavior. International Journal of Engineering Trends and Technology (IJETT), 9, 6

4. Krupnik, L.A, Yelemessov, K. K., Bortebayev, S.A, Baskanbayeva, D.D. (2018). Studying fiber - reinforced concrete for casting housing parts of pumps. EasternEuropean Journal of Enterprise Technologies, 6, 12 (96)

5. V.S. Kostyshyn, I.I. Yaremak, P.O. Kurliak. (2019). Creation of object-oriented model of centrifugal pump on the basis of electrohydrodynamic analogy method. Naukovyi Visnyk Natsionalnoho Hirnychoho Universytetu, 6 